\title{
Treatment Outcome of Tennis Elbow by Percutaneous Needle Tenotomy.
}

Nirab Kayastha ${ }^{1}$, Amit Joshi ${ }^{1}$, Pankaj Chand ${ }^{1}$, Bishnu Babu Thapa ${ }^{1}$, Sushil Rana ${ }^{1}$, Bharat Prasad Singh ${ }^{1}$, Bachhu Ram KC', Bhanu Chandra Shah ${ }^{1}$.

${ }^{1}$ Shree Birendra Hospital, Chhauni, Kathmandu, Nepal

\begin{abstract}
Introduction: Tennis elbow (TE), or lateral epicondylitis of the humerus, is a painful condition seen commonly in the daily practice of Orthopaedic surgeons. One of the myriad of treatment methods for TE is percutaneous needle tenotomy of the common extensor origin. It is a simple operation with minimal morbidity and goodto-excellent results in most of the patients. The aim of this study was to evaluate the outcome in patients with chronic TE. Methods: this was a prospective study in 33 consecutive patients of both sexes with TE who were above 30 years of age. An 18 Gauge hypodermic needle was used under local anaesthesia to percutaneously tenotomise the extensor origin at the point of maximum tenderness. Visual analogue score (VAS) was used to assess the pain prior to intervention and in subsequent follow-ups at first, third, sixth and $12^{\text {th }}$ weeks. Persistence of pain and return to activities of the patients was used to evaluate outcome as excellent, good, fair or poor. Results: At the end of 12 weeks, eleven out of 30 elbows (36.7\%) had an excellent outcome, 13 (43.3\%) had good, $5(16.7 \%)$ had fair and 1 patient $(3.3 \%)$ had poor outcome. At first week follow-up, the mean pain at rest was 4.60 , the same at night was 2.73 and activity pain was a mean of 7.70 (max-9, min-5). By 12 week followup, the mean VAS scores at rest, night and activites were $0.87,0.63$ and 1.53 respectively, showing significant decrease in pain. Conclusions: Percutaneous tenotomy is a simple, safe, patient friendly, effective and easily reproducible method of treating tennis elbow.
\end{abstract}

Keywords: tennis elbow, needle tenotomy, outcome

\section{INTRODUCTION}

Tennis elbow (TE), or lateral epicondylitis is a painful condition of the elbow with pain centered over the common extensor origin of the fingers and wrist. It is sufficiently common and at times disabling condition presenting in Orthopaedic out-patient departments. It occurs during activities that require repetitive supination and pronation of the forearm with the elbow in near full extension. The pathological process mainly involves the origin of the extensor carpi radialis brevis (ECRB), but can involve the tendons of extensor carpi radialis longus (ECRL) and the extensor digitorum communis (EDC $)^{1-4}$.

Many different modalities for treatment of tennis elbow are described: watchful waiting, non-steroidal anti-inflammatory drugs (NSAID), ultrasonography, inotophoresis with NSAID's, braces, acupuncture ${ }^{5,6}$. More than $90 \%$ of patients with TE respond to conservative treatment ${ }^{7}$. Surgery is reserved for resistant cases that have failed to respond to conservative measures, and they include open, mini-open extensor tenotomy $y^{3,7,13}$. Minimally invasive surgical methods have also been described in literature, like percutaneous needle tenotomy, with or without sonography assistance ${ }^{8-11}$. Although needle tenotomy is popular in western couuntries, it has been very infrequently performed in our country. The aim of this study was to evaluate the functional outcome after needle tenotomy.

\section{METHODS}

This was a descriptive study to evaluate the outcome of treatment of tennis elbow by percutaneous needle tenotomy. Diagnosis of TE was made by presence of localized pain

\section{Correspondence:}

Maj. Dr. Nirab Kayastha

Department of Orthopedics, Shree Birendra Hospital.

Kathmandu Nepal.

Email:nirabk@hotmail.com

Phone: +977-9851075278 
or discomfort in the lateral aspect of the elbow, localized tenderness at or just below the lateral epicondyle of the humerus, and positive findings in special tests like Cozen's, Mill's and wring tests.

Patients of both sexes above 30 years of age, who had pain for at least six weeks' duration and whose pain was unresponsive to rest, NSAID's, elbow support or local corticosteroid injections were included in this study. Patients with bilateral epicondylitis and lesions like local skin infection, osteoarthritis of elbow, carpal tunnel syndrome or previous injury to affect the upper limb were excluded from the study.

The patients were seated comfortably on a chair with their forearm resting on examination couch with the elbow flexed to 90 degrees. The point of maximum tenderness is determined and after preparing the entire aspect of the lateral elbow with $70 \%$ ethanol solution, $1 \%$ lignocaine is infiltrated around the entire common extensor origin.

After the local anaesthetic had taken effect, an $18 \mathrm{G}$ needle is introduced through the skin at the previously marked site keeping the bevel of the needle parallel and close to the anterior surface of the lateral epicondyle to a reasonable depth. Then the bevel is used to divide the extensor origin by scraping about 20 degrees up and down from the point of insertion of the needle. The radial nerve is protected by staying within the extensor origin. The needle puncture site is sealed by band aid and a wrist brace is applied.

After the procedure $500 \mathrm{mg}$ to one gm of paracetamol was given four times a day for several days as needed. The wrist brace or sling was advised to be discarded after the pain resolved and normal activities of the limb was advised as soon as possible.

Outcome evaluation was done at $1^{\text {st }}, 3^{\text {rd }}, 6^{\text {th }}$ and 12 week follow-ups. The primary assessment was based on: General assessment of change (on a five-point scale: complete recovery, improved, no change, worse, much worse). Local tenderness (three-point scale: none, some, definite with flinch). Pain on resisted extension of wrist with forearm extended (three-point scale: none, some, definite with flinch).

The results were also scored as: Excellent: full return to all activities with no pain, Good: full return to all activities with occasional mild pain, Fair: no pain with normal activities; significant pain with heavy activities, Poor: little or no relief of pre-operative symptoms ${ }^{8,9,13,14}$. Subjective evaluation of patients' pain was recorded using Visual Analog Scale (VAS) for pain.

\section{RESULTS}

Among the 30 patients, 23 (77\%) were female and 7 (23\%) were male with age ranging from 30 years to 57 years, the mean age being 40.37 years. Among the patitents, 21 patients were right-handed and 9 were left-handed, 15 (50\%) of them being housewives.

Pre-treatment, the minimum VAS score at rest was 1 and the maximum, 8 with a mean of 5.07. Likewise the night pain registered by the patients was minimum 1 and maximum 7. Most of the patients complained of pain mostly during activities - minimum of VAS of 7 and maximum of 10 with mean of 8.50. At first week follow-up, the mean pain at rest was 4.60 , the same at night was 2.73 and activity pain was a mean of 7.70 (max-9, min-5). By 12 week follow-up, the mean VAS scores at rest, night and activites were $0.87,0.63$ and 1.53 respectively, showing significant decrease in pain.

Regarding the change in their condition, at first week, 9 patients said they noticed improvement in their condition, 18 patients did not feel any change and 3 patients felt they were worse off than before treatment. There were no patients who had complete recovery or who were feeling much worse.

At 12 weeks follow-up, 11 patients said they had completely recovered, 18 said they had improved and only one patient had no change in his condition.

At first week, 22 patients had definite tenderness with flinch, at $3^{\text {rd }}$ week ( $2^{\text {nd }}$ follow-up) 6 had tenderness, at $6^{\text {th }}$ week ( $3^{\text {rd }}$ follow-up) only one and by $12^{\text {th }}$ week ( $4^{\text {th }}$ followup) none had tenderness. (Fig. 1)

On resisted extension of wrist 21 patients (70\%) had definite pain with flinch at first week, at three weeks similar pain was experienced by 6 (20\%) patients. At 6 weeks only one patient had such pain, and at 12 weeks none reported pain of that degree. (Fig. 2)

Eleven out of 30 elbows (36.7\%) had an excellent outcome, 13 (43.3\%) had good, 5 (16.7\%) had fair and $1(3.3 \%)$ had poor outcome.

Among the patients three reported post intervention increase in pain, one had hematoma at tenotomy site and four were noted with skin atrophy.

\section{DISCUSSION}

Tennis elbow is commonly encountered problem in daily practice of Orthopaedic surgeons. Many treatment modalities have been proposed for the condition, though $90 \%$ of patients have been recorded to get better 
Fig 1. Local tenderness at different follow-ups

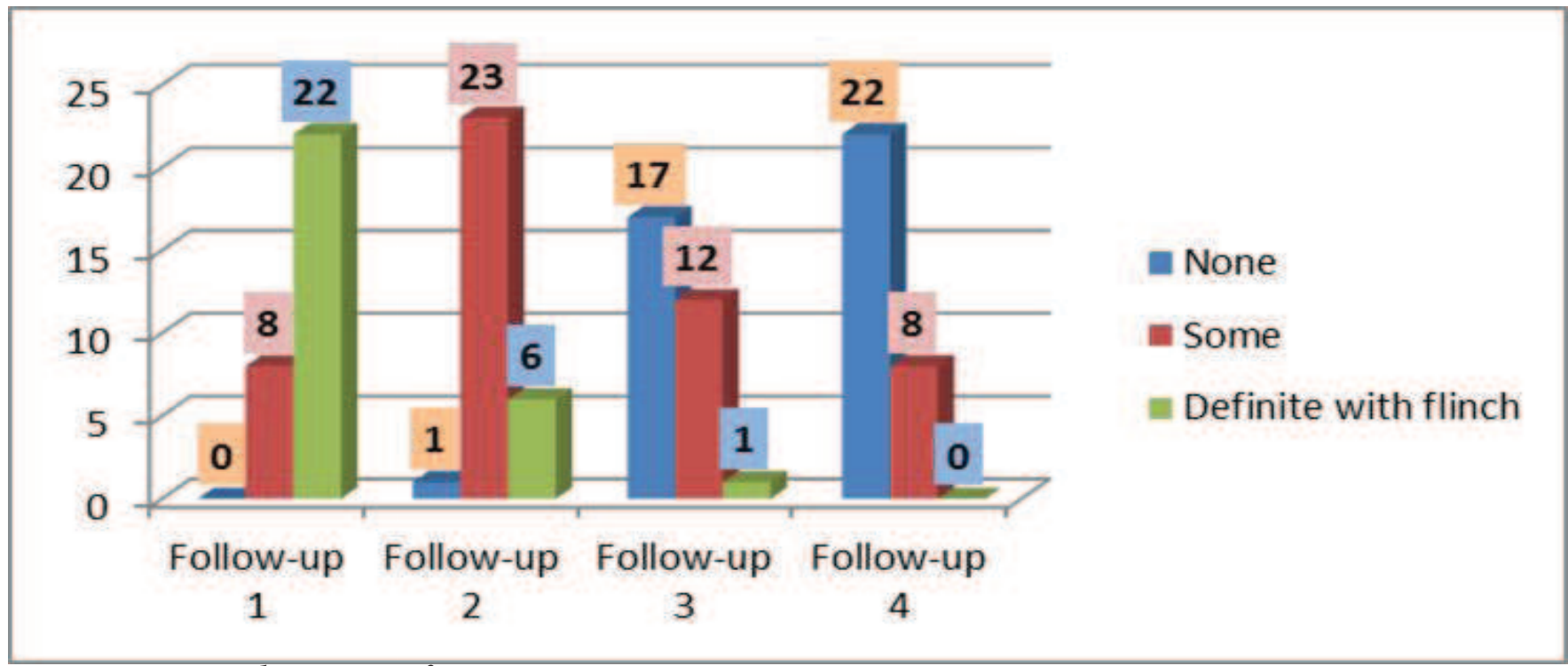

Fig 2: Pain on resisted extension of wrist

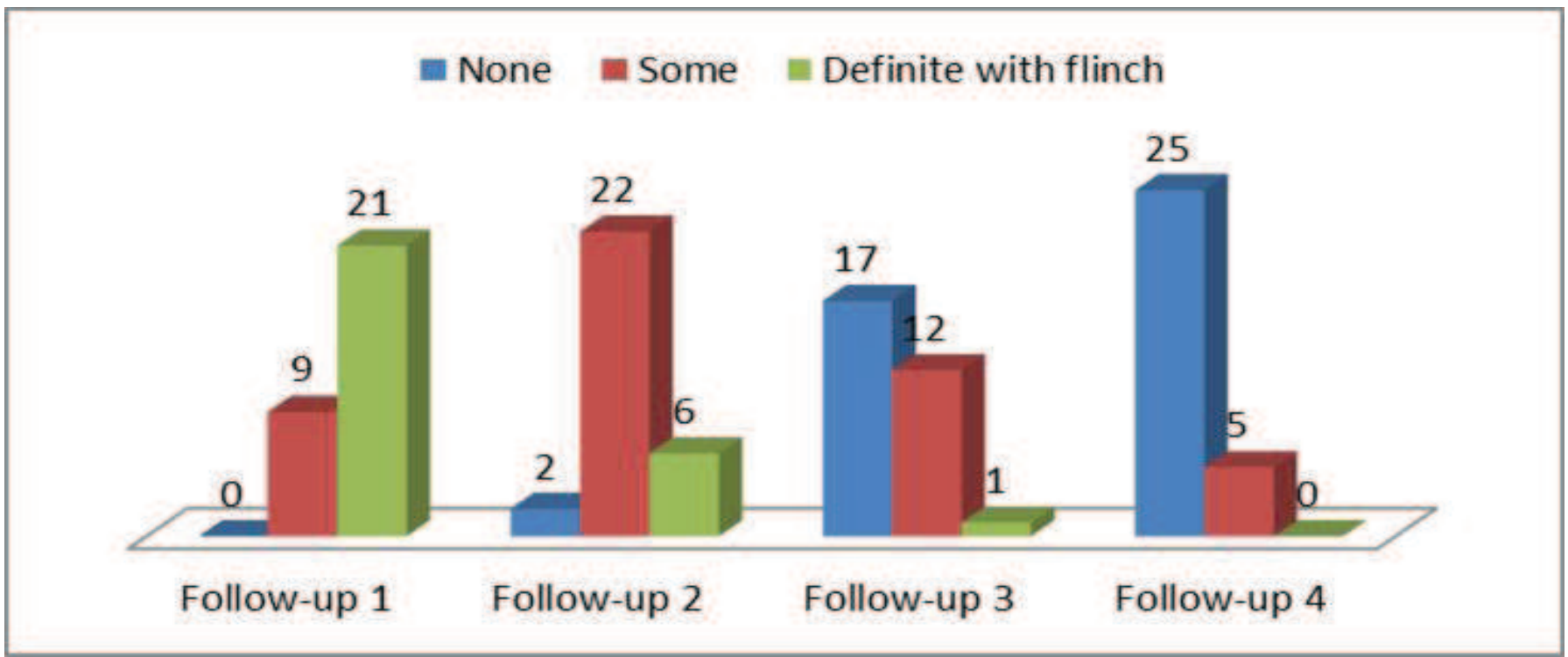

by conservative management ${ }^{7}$. For the unresponsive condition, a minimally invasive surgical technique has been proposed- percutaneous needle tenotomy of the common extensor origin of the forearm muscles ${ }^{8}$.

There are studies of percutaneous needle tenotomy with use of ultrasound guidance ${ }^{10,11}$, but in our set-up the technique used by Lakhey S, Mansfield M and Pradhan $\mathrm{RL}^{8}$ is much more feasible where the procedure is done in outpatient basis by palpating the point of maximum tenderness in the lateral epicondyle and performing percutaneous needle tenotomy with $18 \mathrm{G}$ hypodermic needle under local anaesthesia.

In our study we recruited 33 patients, three of whom were later lost to follow-up. Initially the follow up of the patients at proposed intervals seemed difficult, if not impossible, but when we explained to the patients in detail about the nature of the study, pain scoring method, the assessment of outcomes, it transpired that the assessment could be done via telephone conversation as well when some patient was not able to come to the OPD itself and it contributed to a great extent in timely assessment.

Among the patients, most (23 pts- 76.66\%) were female; and $50 \%$ were housewives, implying the high prevalence of TE among women doing daily household chores. One of the studies have found out that TE among women was associated with low social support at work. ${ }^{12}$ The average age of our patients was 40.37 years. The study also showed that the dominant upper limb was more affected- 21 elbows $(70 \%)$. 
For quantification of pain, we used VAS score as by most of the authors. ${ }^{2,8}$ We followed-up the patients on $1^{\text {st }}, 3^{\text {rd }}, 6^{\text {th }}$ and $12^{\text {th }}$ weeks post-op. Different authors have follow-up protocols ranging from one week to one year ${ }^{9,10}$.

Pre-treatment, the minimum VAS score at rest was 1 and the maximum, 8 with a mean of 5.07. Likewise the night pain registered by the patients was minimum 1 and maximum 7. Most of the patients complained of pain mostly during activities-minimum of VAS of 7 and maximum of 10 with mean of 8.50. On first week after treatment, the mean pain VAS score at rest was 4.60 , pain at night was 2.37 and activity pain was the worst, with a mean of 7.7. By 12 weeks even the pain on activities had decreased to 1.53 in VAS scale.

In the assessment of change in the scale of complete recovery, improved, no change, worse and much worse, at first week, 9 patients (30\%) reported that they had improved, while by 12 weeks 11 patients (36.7\%) had completely recovered, which was a significant change.

Local tenderness also improved by 12 weeks' follow-up: by then 22 patients (73.3\%) had no local tenderness whereas at first week post procedure it was the same number of patients with tenderness graded as "definite with flinch".

As literatures point to it, TE results from gradual degenerative tear of the common extensor origin. ${ }^{2,8}$ Tenotomy of the common extensor tendons and scraping of the epicondylar region using the $18 \mathrm{G}$ needle seems to expediate the healing process of degenerative tendon by converting a chronic inflammatory condition to an acute inflammation which heals rapidly, thereby relieving the pain.

Some complications like increased pain after procedure (3 patients), local skin atrophy in four patients and hematoma at the tenotomy site in one patient were noted. Other possible complications with this procedure are injury to the radial nerve or its branch, wrist extension weakness and drug hypersensitivity with lignocaine injection; last three complications were not seen in our patients.

The small number of patients and the short follow-up period of upto 12 weeks seem to be drawbacks of the study. Recurrence of pain and other parameters cannot be assessed clearly within this time frame.

\section{CONCLUSIONS}

Percutaneous tenotomy using an 18 gauge hypodermic needle is a simple, safe, patient friendly, effective and easily reproducible method of treating tennis elbow. It can be performed in the patients who require surgery and can be done as an outpatient procedure in our settings with limited resources.

\section{REFERENCES}

1. Azar FM. Shoulder and Elbow Injuries. In: Canale ST: Campbell's Operative Orthopaedics. Mosby, Inc. 11th ed, p 2361-2365

2. Bishai SK, Plancher KD. The Basic Science of Lateral Epicondylosis: Update for the Future. Techniques in Orthopaedics. Lippencott Williams \& Wilkins, Inc 21(4):250-255

3. Coonrad RW, Hooper WR. Tennis elbow: its course, natural history, conservative and surgical management. J Bone Joint Surg (Am). 1973;55- A:1177-82.

4. Haahr JP, Andersen JH. Physical and psychosocial risk factors for lateral epicondylitis: a population based case-referent study. Occup Environ Med. 2003;60:322-9.

5. Green S, Buchbinder R, Barnsley L, Hall S, White M, Smidt N, Assendelft $W$. Non-steroidal anti-inflammatory drugs (NSAIDs) for treating lateral elbow pain in adults. Australasian Cochrane Centre, Monash University, Australasian Cochrane Centre, Locked Bag 29, Clayton, Victoria, Australia.sally.green@med.monash.edu.au

6. Leanne Bisset, Elaine BellerGwendolen Jull, Peter Brooks, Ross Darnell, and Bill Vicenzino. Mobilisation with movement and exercise, corticosteroid injection, or wait and see for tennis elbow: randomised trial. BMJ. 2006;333(7575):939.

7. Verhaar J, Walkenkamp G, Kester A et al. Lateral extensor release for tennis elbow. J Bone Joint Surg (Am). 1993;75A:1037-43.

8. Lakhey S, Mansfield M, Pradhan RL, Rijal KP, Pandey BP, Manandhar $R R$. Percutaneous extensor tenotomy for chronic tennis elbow using an $18 G$ needle. Kathmandu Univ Med J (KUMJ). 2007;5(4):446-8.

9. Oztuna V, Milcan A, Eskandari MM, Kuyur F. Percutaneous extensor tenotomy in patients with lateral epicondylitis resistant to conservative treatment. Acta Orthop Traumatol Turc 2002;36:336-340.

10. Jiaan Z, Bing H, Chunyan X, Jia L. Ultrasound-guided, minimally invasive, percutaneous needle puncture treatment for tennis elbow. Advances in Therapy. 2008; 25(10):1031-6.

11. Housner JA, Jacobson JA, Misko R. Sonographically guided percutaneous needle tenotomy for the treatment of chronic tendinosis. $J$ Ultrasound Med. 2009;28(9):1187-92.

12. Haahr JP, Andersen JH. Physical and psychosocial risk factors for lateral epicondylitis: a population based case-referent study. Occup. Environ. Med. 2003;60;322-9.

13. Plancher KD, Bishai SK. Open lateral epicondylectomy: A simple technique update for the 21st century. Techniques in Orthopaedics 2006;21(4):276-82.

14. St. Pierre P, Nirschl RP. Mini-Open Surgical Management of Tennis Elbow Pathology. Techniques in Orthopaedics. 2006;21(4):266-275. 